\title{
Comparison between Pap smear and visual inspection with acetic acid in screening of premalignant cervical intraepithelial lesion and subclinical early cancer cervix
}

\author{
Hossam Hassan Aly Hassan El Sokkary*
}

Department of Obstetrics and Gynecology, Alexandria University, Egypt

Received: 26 October 2016

Accepted: 28 November 2016

\section{*Correspondence:}

Dr. Hossam Hassan Aly Hassan El Sokkary,

E-mail: hossamsokkary@ hotmail.com

Copyright: (c) the author(s), publisher and licensee Medip Academy. This is an open-access article distributed under the terms of the Creative Commons Attribution Non-Commercial License, which permits unrestricted non-commercial use, distribution, and reproduction in any medium, provided the original work is properly cited.

\begin{abstract}
Background: The objective of the study was to compare the sensitivity, specificity, positive predictive value and negative predictive value of VIA and Pap smear in screening of premalignant cervical intraepithelial lesion and subclinical early cancer cervix.

Methods: An observational prospective study was done for 350 patients attending the gynecology outpatient clinic of the shatby maternity university hospital for any reasons, VIA and Pap test were done for all patients, then colposcopic guided biopsy from cases with positive colposcopic findings. Histopathological examination was done for collected biopsy. Collected data was statistically analyzed to compare between both tests (PAP and VIA).

Results: Our results showed that the sensitivity of PAP test was $83.3 \%$, specificity was $90.7 \%$, positive predictive value was $50.8 \%$, negative predictive value was $97.9 \%$ and accuracy was $90 \%$ while the VIA test had a sensitivity of $66.7 \%$, specificity was $91 \%$, positive predictive value was $46.1 \%$, negative predictive value was $95.9 \%$ and accuracy was $88.5 \%$.

Conclusions: Via test has comparable results to Pap test regarding its sensitivity, specificity, positive predictive value, negative predictive value and accuracy and can be used as an alternative primary test to screen premalignant cervical intraepithelial lesion and subclinical early cancer cervix.
\end{abstract}

Keywords: Cervical intraepithelial lesion, Cancer, Pap smear, Premalignant

\section{INTRODUCTION}

Cancer cervix is the third most common genital tract cancer in developed countries, the second most common and the leading cause of death from cancer in developing countries after cancer breast in women. ${ }^{1,2}$ In the United States, cervical cancer is not common, the incidence of invasive cancer cervix has reduced continuously in the US over the past years; for example, since 2004, incidence has decreased by $3.1 \%$ per year in women 50 years of age and older and $2.1 \%$ per year in women younger than 50 years. In developed countries with cylogical screening programs using Pap smear, the incidence of cancer cervix is from 4 to 10 per 100,000 women. ${ }^{3}$ Up to 1 million American women are diagnosed with cervical intraepithelial neoplasm (CIN) every year. The most common age that CIN develop ranges between 25 to 35 years old. ${ }^{4}$ There are many convincing epidemiological data proved that using Pap smear in countries with wide population coverage and organized screening programs lead to reduction in the incidence of invasive cervical cancer and its mortality. ${ }^{5}$ Although Pap`s smear is an effective method to screen CIN and early subclinical invasive lesion, it is not cost effective especially in poor developing countries. ${ }^{6}$ Other limitations of Pap`s smear that it needs well trained staff 
to collect the samples, well trained cytopathologist to interpret the samples, that's why Pap smear is not suitable in developing countries. ${ }^{7}$

Vaginal inspection with acetic acid is a simple screening procedure done by naked eye using acetic acid 3\% to $5 \%$ or vinegar painting of cervical transformation zone during speculum examination, acetic acid reversibly coagulates nuclear protein lead to white discoloration of transformation zone in CIN and early invasive cancer, that's why it is a simple, cost effective screening test that can be used in poor developing countries with high invasive cancer cervix mortality incidence. ${ }^{8,9}$ But we need to evaluate its sensivity and specificity in CIN and early invasive subclinical cancer cervix diagnosis and to compare it with Pap`s smear. The aim of the article is to compare the sensitivity, specificity, positive predictive value and negative predictive value of VIA and Pap smear in screening of premalignant cervical intraepithelial lesion (CIN) and subclinical early cancer cervix and to evaluate the clinical performance of visual inspection with acetic acid (VIA) as a simple test and if it is a low cost alternative to PAP smear.

\section{METHODS}

A prospective observational study was done for 350 patients attending the gynaecology outpatient clinic in Shatby maternity university hospital.

Following approval by our institutional ethics committee, an observational prospective study was done for 350 patients attending the gynaecology outpatient clinic of the shatby maternity university hospital for any reasons expect patients with total abdominal hysterectomy, suspicious cervix or frank cervical lesions, menstruation, attack of abnormal uterine bleeding and unmarried patients. Patients enrolled in the study, were explained at first the procedure which was done and a written informed consent was taken from them. At first, a cytological Pap smear was taken with Ayre's spatula by transformation zone scraping and supplemented by endocervical sample using cotton wool swap, both are spreaded in the same slide, fixed by immersion in alcohol $90 \%$ for one hour and sent to lab and the results were interpreted according to the Bethesda system. After the Pap smear, VIA test was done with $3-5 \%$ acetic acid. Results of VIA were recorded after waiting for 1 minute as negative, or positive. VIA positive sign include sharp distinct well-defined, dense (opaque/dull or oyster white) acetowhite areas with or without raised margins touching the squamocolumnar junction. ${ }^{10,11}$

Colposcopic guided punch biopsy was done for all patients with positive colposcopic finding as punctuate pattern or mosaic pattern, abnormal vasculature or acetowhite area. Punch biopsy was taken from acetowhite area of distinct margin touching the squamocolumnar junction, mosaic pattern, punctuate pattern and abnormal vasculature. ${ }^{12,13}$ Unsatisfactory colposcopic examination as unseen squamocolumnar junction was supplemented by endocervical curettage histopathological examination was done for collected biopsy. ${ }^{14}$ Collected data was statistically analysed to determine and to compare the sensitivity, specificity, positive predictive value and negative predictive value of VIA and Pap smear in screening of premalignant cervical intraepithelial lesion and subclinical early cancer cervix.

\section{Statistical analysis}

The Data was collected and entered into the personal computer. Statistical analysis was done using Statistical Package for Social Sciences (SPSS/version 20) software.

\section{The prognostic value of the tests determined by:}

- Sensitivity of the test: the percent of the positives by the test and the true positives.

- Specificity of the test: the percent of the negatives by the test and the true negatives.

- Positive predictive value: the percent of the true positives and all the positives by the test.

- Negative predictive value: the percent of the true negatives and all the negatives by the test.

- Accuracy: the percent of agreement between the two tests.

Monte Carlo test was used to compare between prognostic value of both tests.

\section{Justification of the sample}

Based on other Papers findings a total sample size of 350 cases is required to elicit the difference at alpha level of 0.05 and a study power of $80 \%$.

\section{RESULTS}

Table 1 showed that out of 350 cases included in the study $251(71.1 \%)$ had normal smears, 40 cases $(11.4 \%)$ had inflammatory results and 59 cases (16.9\%) with atypical cells (positive PAP smear). The 59 positive PAP test cases $(16.9 \%)$ distributed according to Bethesda system as follows 10 cases (2.9\%) with atypical squamous cell of undetermined significance (ASCUS), 36 cases $(10.3 \%)$ with low grade squamous intraepithelial lesion (LSIL) and 13 cases (3.7\%) with high-grade Squamous Intraepithelial Lesion(HSIL). Regarding the histopathological results of the 59 positive PAP test cases, the 10 ASCUS cases, 9 of them had no CIN OR carcinoma in situ (CIS) and one case had CIN 1, in relation to the 36 LSIL cases, 20 of them had no CIN or CIS and 16 cases had CIN 1, as regards the 13 HSIL cases, 7 of them had CIN 2, 5 cases had CIN 3 and 1 case 
had CIS. Total number of cases without atypical cells including normal and inflammatory smears cases was 291 cases $(83.1 \%)$ out of 350 patients enrolled in the study.

Table 1: Pap test results and histopathological examination of biopsy from cases with atypical cell of any Bestheda system types.

\begin{tabular}{|lll|}
\hline PAP smear results & Number & percentage \\
\hline Normal & 251 & 71.7 \\
\hline Inflammatory & 40 & 11.4 \\
\hline $\begin{array}{l}\text { ASCUS } \\
\text { Histopathological types }\end{array}$ & 10 & 2.9 \\
$\begin{array}{l}\text { No CIN or CIS } \\
\text { CIN 1 }\end{array}$ & 9 & 2.6 \\
\hline $\begin{array}{l}\text { LSIL } \\
\text { Histopathological types }\end{array}$ & 1 & 0.3 \\
$\begin{array}{l}\text { NO CIN or CIS } \\
\text { CIN 1 }\end{array}$ & 20 & 10.3 \\
\hline $\begin{array}{l}\text { HSIL } \\
\text { Histopathological types }\end{array}$ & 16 & 5.7 \\
$\begin{array}{l}\text { CIN 2 } \\
\text { CIN 3 }\end{array}$ & 7 & 3.7 \\
CIS & 5 & 2.0 \\
\hline $\begin{array}{l}\text { Total number of cases } \\
\text { with atypical cells }\end{array}$ & 59 & 1.4 \\
\hline $\begin{array}{l}\text { Total number of cases } \\
\text { without atypical cells } \\
\text { (pathology) }\end{array}$ & 291 & 83.1 \\
\hline $\begin{array}{l}\text { Total patient enrolled in } \\
\text { the study }\end{array}$ & 350 & $100 \%$ \\
\hline
\end{tabular}

Table 2 showed that 52 cases (14.9\%) out of 350 cases had positive VIA test, the histopathological result of these case were as follow: 28 cases $(8 \%)$ had no CIN or CIS, 13 cases $(3.7 \%)$ had CIN 1,5 cases $(1.4 \%)$ had CIN 2, 5 cases $(1.4 \%)$ had CIN 3 and one case $(0.3 \%)$ had CIS. The VIA negative test were 298 cases $(85.1 \%)$ out of 350 cases enrolled in the study.

Table 3 represent correlation of PAP test results with suspicious colposcopic findings cases and histopathological examination, 30 cases out of 59 positive PAP cases had CIN or CIS, 29 PAP positive cases had no CIN or CIS, 6 case is PAP negative but positive on VIA test and suspicious on colposcopy had CIN or CIS in comparison to 11 cases negative on PAP test but positive on VIA test and suspicious on colposcopy had no CIN or CIS.

Table 2: VIA test results and histopathological examination of biopsy from cases with positive VIA test.

\begin{tabular}{|lll|}
\hline VIA test & Number & percentage \\
\hline VIA positive & 52 & 14.9 \\
\hline Histopathological types & & \\
No CIN & 28 & 8.0 \\
CIN 1 & 13 & 3.7 \\
CIN 2 & 5 & 1.4 \\
CIN3 & 5 & 1.4 \\
CIS & 1 & 0.3 \\
\hline VIA negative & 298 & 85.1 \\
\hline Total number & 350 & 100.0 \\
\hline
\end{tabular}

Table 3: Correlation of Pap test with histopathological examination of suspicious colposcopic findings cases.

\begin{tabular}{|c|c|c|c|}
\hline PAP test & $\begin{array}{l}\text { Cloposcopic suspicious finding cases } \\
\text { and histopathological examination } \\
\text { positive (CIN or CIS) }\end{array}$ & $\begin{array}{l}\text { Cloposcopic suspicious finding cases } \\
\text { and histopathological examination } \\
\text { negative (No CIN or CIS) }\end{array}$ & Total \\
\hline $\begin{array}{l}\text { Positive Pap test } \\
\text { (presence of } \\
\text { atypical cells) }\end{array}$ & 30 & 29 & 59 \\
\hline $\begin{array}{l}\text { Negative Pap test } \\
\text { (absence of atypical } \\
\text { cells) }\end{array}$ & 6 & 11 & 17 \\
\hline Total & 36 & 40 & 76 \\
\hline
\end{tabular}

Table 4: Correlation of via test with histopathological examination of suspicious colposcopic findings cases.

\begin{tabular}{|llll|}
\hline VIA test & $\begin{array}{l}\text { Cloposcopic suspicious finding cases } \\
\text { and histopathological examination } \\
\text { positive (CIN or CIS) }\end{array}$ & $\begin{array}{l}\text { Cloposcopic suspicious finding cases } \\
\text { and histopathological examination } \\
\text { negative (No CIN or CIS) }\end{array}$ & $\begin{array}{l}\text { Total } \\
\text { Positive VIA test }\end{array}$ \\
\hline Negative via test & 12 & 28 & 52 \\
\hline Total & 46 & 12 & 24 \\
\hline
\end{tabular}


Table 4 showed correlation of VIA test with suspicious colposcopic findings cases and histopathological examination, 24 cases out of 52 VIA positive cases had CIN or CIS, 28 VIA positive cases had no CIN or CIS, 12 cases were negative on VIA but suspicious on colposcopy and positive on PAP test had CIN or CIS in comparison to 12 cases were negative on VIA test but positive on PAP and suspicious on colposcopy test had no CIN or CIS.

Table 5: Sensitivity, specificity, PPV, NPV and accuracy of Pap test in relation to histopathological results of colposcopic suspicious findings cases.

\begin{tabular}{|c|c|c|c|}
\hline PAP test & $\begin{array}{l}\text { Cloposcopic suspicious } \\
\text { finding cases and } \\
\text { histopathological positive }\end{array}$ & $\begin{array}{l}\text { Cloposcopic suspicious finding cases } \\
\text { and histopathological negative }\end{array}$ & Total \\
\hline Positive PAP test & 30 & 29 & 59 \\
\hline Negative PAP test & 6 & 285 & 291 \\
\hline Total & 36 & 314 & 350 \\
\hline Sensitivity & 83.3 & & \\
\hline Specificity & 90.7 & & \\
\hline Positive predictive value & 50.8 & & \\
\hline Negative predictive value & 97.9 & & \\
\hline Accuracy & 90.0 & & \\
\hline
\end{tabular}

Table 6: Sensitivity, specificity, PPV, NPV and accuracy of VIA test in relation to histopathological results of colposcopic suspicious findings cases.

\begin{tabular}{|c|c|c|c|}
\hline VIA test & $\begin{array}{l}\text { Cloposcopic suspicious } \\
\text { finding cases and } \\
\text { histopathological positive }\end{array}$ & $\begin{array}{l}\text { Cloposcopic suspicious finding cases and } \\
\text { histopathological negative }\end{array}$ & Total \\
\hline Positive VIA test & 24 & 28 & 52 \\
\hline Negative VIA test & 12 & 286 & 298 \\
\hline Total & 36 & 314 & 350 \\
\hline Sensitivity & 66.7 & & \\
\hline Specificity & 91.0 & & \\
\hline Positive predictive value & 46.1 & & \\
\hline Negative predictive value & 95.9 & & \\
\hline Accuracy & 88.5 & & \\
\hline
\end{tabular}

Table 7: Comparison between the sensitivity, specificity, positive predictive value, negative predictive value and accuracy of PAP and VIA test.

\begin{tabular}{|llll|}
\hline & PAP test & VIA test & p \\
\hline Sensitivity & 83.3 & 66.7 & 0.071 \\
Specificity & 90.7 & 91.0 & 0.625 \\
Positive predictive value & 50.8 & 46.1 & 0.584 \\
Negative predictive value & 97.9 & 95.9 & 0.698 \\
Accuracy & 90.0 & 88.5 & 0.701 \\
\hline
\end{tabular}

Table 5 showed sensitivity, specificity, positive predictive value, negative predictive value of Pap test in relation to histopathological result of colposcopic suspicious findings cases, the sensitivity was $83.3 \%$, specificity was $90.7 \%$, positive predictive value was
$50.8 \%$, negative predictive value was $97.9 \%$ and accuracy was $90 \%$.

Table 6 showed sensitivity, specificity, positive predictive value, negative predictive value of VIA test in relation to histopathological findings of colposcopic 
suspicious findings cases, the sensitivity was $66.7 \%$, specificity was $91 \%$, positive predictive value was $46.1 \%$, negative predictive value was $95.9 \%$ and accuracy was $88.5 \%$.

Table 7 represented a comparison between the sensitivity, specificity, positive predictive value, negative predictive value and accuracy of PAP and VIA test ,the table showed that's there were no significant difference between both test in relation to sensitivity $(\mathrm{p}=0.071)$, specificity $(\mathrm{p}=0.625)$, positive predictive value $(\mathrm{p}=0.584)$, negative predictive value $(\mathrm{p}=0.698)$ and accuracy $(\mathrm{p}=0.701)$.

\section{DISCUSSION}

Invasive cancer cervix is considered now as a preventable disease, PAP smear test is proved to be an effective screening method for early preinvasive change that precede invasive cancer especially when applied in an systematic organized regular set and has a wide coverage. ${ }^{15}$ Cost and effectiveness of many various preventive strategies are therefore of great concern for health policy makers, other screening tools include human Papilloma virus (HPV) testing alone or in combination with annual PAP smear and VIA test. ${ }^{16}$ HPV testing is not cost effective especially in developing countries. ${ }^{17}$ Although Pap smear is effective in screening, it has many limitations as trained staff for samples collection and trained cytopathologist for result interpretation which are a difficult prerequisite in poor developing countries. ${ }^{7}$ VIA test is a simple test that can be used in developing countries or when there is a need for cost effective method with wide covering. Many studies have been done to compare PAP to VIA smears for cervical cancer screening. Most of them were looking at sensitivities and specificities for both tests, Consul S1 et al studied the effectiveness of the Pap smear, VIA test and visual inspection with Lugol's iodine (VILI) for mass screening of CIN and early subclinical cervical cancer and found that VIA and VILI had sensitivity comparable to Pap smear and can thus be a suitable potential alternative/adjunctive screening test not only in a resource-poor setting but in well-equipped centers also. ${ }^{18}$ Doh et al examined VIA test as a screening tool for cancer cervix in Africa, where cancer cervix is the second common cause of death after cancer breast in women. VIA and Pap smear was done for all patients, and colposcopic biopsy were done for positive test cases only. Sensitivity of VIA was $70.4 \%$ compared to $47.7 \%$ for PAP. VIA specificity was $77.6 \%$ compared to $94.2 \%$ for PAP. PPV of VIA was $44 \%$ and NPV was $91.3 \%$. Doh concluded that PAP smear was more specific but not sensitive as VIA test but both were compared to each other and VIA test can be used in low resource settings as in poor developing countries to screen wide mass population. ${ }^{19}$ Another study was done by Goel in India for 400 women attending the gynaecological outpatient clinic in New Delhi and found that the sensivity of VIA test was $96.7 \%$ compared to $50 \%$ for PAP test and specificity was $36.4 \%$ compared to 97 for PAP test and the conclusion was that VIA test has a very high sensivity and very low cost that make it suitable for a primary screening test for cervical premalignant lesions in poor developing countries. ${ }^{20}$ Our results showed that the sensitivity of PAP test was $83.3 \%$, specificity was $90.7 \%$, positive predictive value was $50.8 \%$, negative predictive value was $97.9 \%$ and accuracy was $90 \%$ while the VIA test has a sensitivity of $66.7 \%$, specificity was $91 \%$, positive predictive value was $46.1 \%$, negative predictive value was $95.9 \%$ and accuracy was $88.5 \%$. In contrast to others study, sensitivity in our results was higher in PAP test than in VIA test and specificity was higher in VIA test than PAP test, the explanation of that was the followings:

1. All cases with atypical cells including cases with ASCUS were included and considered as positive PAP test cases in contrary to others studies which excluded these cases as Consul S1 et al study so it lead to increase sensitivity and decrease specificity of PAP test. ${ }^{18}$

2. VIA positive cases included only cases with sharp distinct well-defined, dense (opaque/dull or oyster white) acetowhite areas with or without raised margins touching the squamocolumnar junction so cases with faint acetowhite area or not well defined border touching the squamocolumnar junction were considered negative VIA test cases and this lead to decrease sensitivity of VIA test and increase specificity of it.

As regards comparison between the sensitivity, specificity, positive predictive value, negative predictive value and accuracy of PAP and VIA test, the results showed no significant difference between both tests and results of them were well compared to each other, so we can conclude that VIA test has a comparable results to PAP test and can be used as an alternative primary test to screen premalignant cervical lesions of cervix especially in poor developing countries

\section{CONCLUSION}

Via test has comparable results to Pap test regarding its sensitivity, specificity, positive predictive value, negative predictive value and accuracy and can be used as an alternative primary test to screen premalignant cervical intraepithelial lesion and subclinical early cancer cervix.

\section{Funding: No funding sources \\ Conflict of interest: None declared \\ Ethical approval: The study was approved by the Institutional Ethics Committee}

\section{REFERENCES}

1. Jemal A, Bray F, Center MM, Ferlay J, Ward E, Forman D. Global cancer statistics. CA Cancer J Clin. 2011;61(2):69-90. 
2. Siegel R, Ward E, Brawley O, Jemal A. Cancer statistics: the impact of eliminating socioeconomic and racial disparities on premature cancer deaths. CA Cancer J Clin. 2011;61(4):212.

3. Solomon D, Breen N, McNeel T. Cervical cancer screening rates in the United States and the potential impact of implementation of screening guidelines. CA Cancer J Clin. 2007;57(2):105-11.

4. Kumar V, Abul AK. Robbins Basic Pathology. 2007;8:718-21.

5. Kitchener HC, Castle PE, Cox JT. Achievements and limitations of cervical cytology screening. Vaccine. 2006;24 3:S63-70.

6. Moyer VA. U.S. Preventive Services Task Force: Screening for cervical cancer: U.S. Preventive Services Task Force recommendation statement. Ann Intern Med. 2012;156(12):880-91.

7. Eversole GM, Moriarty AT, Schwartz MR, Clayton AC, Souers R, Fatheree LA, et al. Practices of participants in the college of american pathologists interlaboratory comparison program in cervicovaginal cytology, 2006. Archives of pathology \& laboratory medicine. 2010;134(3):3315.

8. Sankaranarayanan R, Gaffikin L, Jacob M. A critical assessment of screening methods for cervical neoplasia. International Journal of Gynecology \& Obstetrics. 2005;89:4-12.

9. Ferlay J, Soerjomataram I, Dikshit R, Eser S, Mathers C, Rebelo M. Cancer incidence and mortality worldwide: sources, methods and major patterns in GLOBOCAN 2012. Int $\mathrm{J}$ Cancer. 2015;136:359-86.

10. Sankaranarayanan R, Wesley R, Somanathan T, Dhakad N, Shyamalakumary B, Amma NS. Visual inspection of the uterine cervix after the application of acetic acid in the detection of cervical carcinoma and its precursors. Cancer. 1998;83:2150-6.

11. Gaffikin L, Lauterbach M, Blumenthal PD. Performance of visual inspection with acetic acid for cervical cancer screening: A qualitative summary of evidence to date. Obstetrical and Gynaecological Review. 2003;58(8):543-50.

12. García-Arteaga JD, Kybic J, Li W. Automatic colposcopy video tissue classification using higher order entropy-based image registration. Comput Biol Med. 2011;41(10):960-70.

13. Noller K, Wagner A Jr. Colposcopy. Sciarra JL, ed. Gynecology and Obstetrics. Philadelphia, Pa: Lippincott, Williams and Wilkins. 2000.

14. Abu J, Davies Q. Endocervical curettage at the time of colposcopic assessment of the uterine cervix. Obstet Gynecol Surv. 2005;60(5):315-20.

15. ACOG Practice Bulletin No. 131: Screening for Cervical Cancer. ACOG Committee on Practice Bulletins-Gynecology. Obstet Gynecol. 2012;120(5):1222-38.

16. Denny L, Kuhn L, Pollack A, Wainwright H, Wright TC. Evaluation of alternative methods of cervical cancer screening for resource-poor settings. Cancer. 2000;89:826-33.

17. Chen MK, Hung HF, Duffy S, Yen AM, Chen HH. Cost-effectiveness analysis for Pap smear screening and human Papillomavirus DNA testing and vaccination. J Eval Clin Pract. 2011;17(6):1050-8.

18. Consul S, Agrawal A, Sharma H, Bansal A, Gutch M, Jain N. Comparative study of effectiveness of Pap smear versus visual inspection with acetic acid and visual inspection with Lugol's iodine for mass screening of premalignant and malignant lesion of cervix. Indian J Med Paediatr Oncol. 2012;33(3):161-5.

19. Doh AS. Visual Inspection with acetic acid and cytology as screening methods for cervical lesions in Cameroon. Int J Gynecol Obstet. 2005:89.

20. Goel A, Gandhi G, Batra S. Visual Inspection of the cervix with acetic acid for cervical intraepithelial lesions. Int J Gynecol Obstet. 2005;88:25-30.

Cite this article as: Sokkary HH. Comparison between Pap smear and visual inspection with acetic acid in screening of premalignant cervical intraepithelial lesion and subclinical early cancer cervix. Int J Reprod Contracept Obstet Gynecol 2017;6:54-9. 